\title{
Effect of synthesis atmosphere on the proton conductivity of Y-doped barium zirconate solid electrolytes
}

\author{
M.D. Gonçalves ${ }^{\mathrm{a}, \mathrm{b}}$, Pardha S. Maram ${ }^{\mathrm{b}}$, A. Navrotsky ${ }^{\mathrm{b}}$, R. Muccillo ${ }^{\mathrm{a}^{*}}$ \\ ${ }^{a}$ Center of Science and Technology of Materials, Energy and Nuclear Research \\ Institute, Travessa R 400, Cidade Universitária, S. Paulo, SP 05508-170, Brazil \\ ${ }^{\mathrm{b}}$ Peter A. Rock Thermochemistry Laboratory and NEAT ORU, University of \\ California Davis, Davis, CA 95616, USA \\ mayradg@usp.br, navrotsky@ucdavis.edu, muccillo@usp.br
}

\begin{abstract}
Yttrium-doped barium zirconate ceramic powders were synthesized by the oxidant peroxide method in air and under controlled atmosphere of nitrogen inside a glove box. The powders were characterized by thermogravimetry, X-ray diffraction, scanning electron microscopy and transmission electron microscopy. After uniaxial cold isostatic pressing, green pellets were sintered at $1600{ }^{\circ} \mathrm{C}$ for $4 \mathrm{~h}$. The electrical conductivity behaviour was accessed by electrochemical impedance spectroscopy. The results show that specimens synthesized under controlled atmosphere achieved higher electrical conductivity, two orders of magnitude higher than specimens prepared in laboratory air. The enhancement in electrochemical properties and increase in sintering ability is attributed to the less carbonate contamination as a result lower grain boundary density in the samples prepared under controlled atmosphere.
\end{abstract}


Keywords: proton conductor; barium zirconate; powder synthesis; impedance spectroscopy.

*Corresponding Author.

\section{Introduction}

Solid oxide fuel cells (SOFCs) have attracted increased attention due to their high conversion efficiency of chemical energy into electricity with low environmental impact, compared to fuel combustion [1-5]. SOFCs are also a sustainable alternative to energy production over other hydrogen-based technologies. Even though hydrogen does not contribute to the greenhouse effect, this element is not available in the environment in the sense that expensive methods must be employed for its synthesis, separation and purification. In addition, hydrogen handling and storage have to be carefully addressed because of safety issues. This is the main reason for continuing research to find new solutions for hydrogen production, which could be achieved under solid oxide fuel cell operation, fueling the cell with hydrogen containing species (internal reform). Since cell operation occurs at high temperatures $\left(800-1000{ }^{\circ} \mathrm{C}\right)$, methane and hydrocarbons can be directly injected into the cell for in situ production of hydrogen, which is then consumed for electricity production. The most developed and commercially available SOFCs are based on oxygen ion conducting solid electrolytes and the operating temperature is in the $600-1000{ }^{\circ} \mathrm{C}$ range [5]. Yttria-stabilized zirconia $\left(\mathrm{ZrO}_{2}: 8\right.$ mol\% $\left.\mathrm{Y}_{2} \mathrm{O}_{3}\right)$ is considered the state-of-the-art solid electrolyte for high temperature SOFCs. This electrolyte has predominant ionic conduction 
reaching $0.1 \mathrm{~S} / \mathrm{cm}$ at $1000{ }^{\circ} \mathrm{C}$. However, there are several problems associated with the high temperature, including thermal expansion mismatch of components, cell poisoning and degradation due to $\mathrm{CO}$ and $\mathrm{CO}_{2}$ formation leading to carbon deposition (coking), decreasing cell performance and lifetime [6-8]. Therefore, efforts continue to reduce SOFC working temperature to an intermediate range $\left(650-850^{\circ} \mathrm{C}\right.$, ITSOFC) $[9,10]$ and even a lower range (400$650{ }^{\circ} \mathrm{C}$. LTSOFC [11].

Oxides with perovskite structure based on barium cerate and barium zirconate, and a combination of both (BCX, BZX e BCZX, X = trivalent cation $\mathrm{Y}^{3+}, \mathrm{Gd}^{3+}$ ) are proposed for application as solid electrolytes in ITSOFCs. In addition, yttrium-doped barium zirconate (BYZ) has also been proposed as the best choice due to its high chemical stability under $\mathrm{CO}_{2}$-rich atmospheres and high mechanical resistance, and high proton conductivity at intermediate temperatures [12-15]. Indeed, the bulk conductivity at $500{ }^{\circ} \mathrm{C}$ of barium zirconate containing $20 \mathrm{~mol} \% \mathrm{Y}^{3+}$ in solid solution (BZY20) is comparable to the conductivity of gadolinium-doped ceria $\left(\mathrm{Ce}_{0.9} \mathrm{Gd}_{0.1} \mathrm{O}_{2-\delta}\right)$, which is one of the best oxygen-ion conductors [12]. However, the major concern is on the total proton conductivity, i.e., bulk and grain boundary conductivities. Due to the refractory nature of BZY, it has limited grain growth during sintering, which leads to a high density of grain boundaries and a high electrical resistivity. BZY powders are usually synthesized by solid state reaction of the precursor oxides, which generally leads to nonstoichiometric compounds. Moreover, the specimens must be exposed to aggressive sintering conditions to obtain pellets with density high enough for use as solid electrolytes in ITSOFCs. The conditions 
involving very high temperatures and long dwell times for synthesis and sintering $\left(>1700{ }^{\circ} \mathrm{C},>24 \mathrm{~h}\right.$ ) lead to barium loss, resulting in electrical conductivity decrease [16]. This is the major drawback when developing electrochemical devices based on barium zirconate. Therefore, the main challenge is to achieve dense ceramic bodies, while applying sintering conditions that could inhibit barium loss with lower grain boundary electrical resistivity [14,16-18].

Many synthesis and processing techniques have been applied for making better quality solid electrolytes: wet-chemical synthesis, co-doping, and sintering aids, among others. Very recently, BZY protonic ceramic fuel cells with high power output have been reported using BZY solid electrolytes sintered with CuO sintering aid [19]. Wet-chemical routes have already been used to produce powder particles with higher sinterability to obtain pellets sintered at relatively low temperatures $[16,18,20-24]$. A total proton conductivity of $\sim 0.01 \mathrm{~S} / \mathrm{cm}$ at 450 ${ }^{\circ} \mathrm{C}$ in a polycrystalline BZY20 sample produced by a sol-gel route was reported. The high proton conductivity was achieved in large-grain samples produced from a nanocrystalline precursor and reactive sintering (in presence of $\mathrm{BaCO}_{3}$ ) [25]. The decrease of proton conductivity in BZY compounds containing higher than $20 \mathrm{~mol} \%$ yttrium is related to the reduced symmetry due to lattice distortions, increased oxygen basicity $\left(\mathrm{Y}^{3+}\right.$ is less electronegative than $\left.\mathrm{Zr}^{4+}\right)$ and proton trapping effects due to the formation of dopant-defect associates which reduce the mobility of charge carriers [26-32].

Among the synthetic routes, the oxidant peroxide method (OPM) is also very promising since it is free from common contaminants such as carbon 
or halides [33]. Besides, this method allows the formation of stoichiometric powders with reactive nanoparticles [33-38]. In the present work, experiments were carried out on the synthesis by the oxidant peroxide method of $\mathrm{BaZr}_{0.9} \mathrm{Y}_{0.1} \mathrm{O}_{3-\delta}$ following two approaches: i) under usual laboratory air and ii) under controlled nitrogen atmosphere inside a glove box. The main idea was to compare sintered ceramic pellets prepared with powders subjected to these two atmosphere conditions, aiming to avoid the formation of aggregates of the powder particles, known to be due to the presence of chemical species attached to the as precipitated precursor particles [39]. It is expected that powders with cleaner particle surfaces should produce better sintering conditions for obtaining pellets with improved electrical properties. Morphological and electrical characterizations were performed on the sintered pellets.

\section{Material and Methods}

Ceramic powders of composition $\mathrm{BaZr}_{0.9} \mathrm{Y}_{0.1} \mathrm{O}_{3-\delta}(\mathrm{BZY} 10)$ were synthesized by the oxidant peroxide method (OPM) by two different approaches: (i) in laboratory air, referred hereafter as AIR, and (ii) inside a glove box under nitrogen atmosphere, referred as $\mathrm{N}_{2}$. The starting materials and the synthesis procedure have been described elsewhere $[31,38]$.

\section{1 - AlR powders}

The precursor powders obtained by the synthesis in air were calcined at $900{ }^{\circ} \mathrm{C} / 4 \mathrm{~h}$ and $1200^{\circ} \mathrm{C} / 2 \mathrm{~h}$ with $10^{\circ} \mathrm{C} / \mathrm{min}$ heating and cooling rates. 
Thermogravimetric analyses of the precursor powder were performed in a Netzsch STA 409E thermal analyzer. About $60 \mathrm{mg}$ of sample was heat treated from 25 to $1200{ }^{\circ} \mathrm{C}$ with heating rate of $10{ }^{\circ} \mathrm{C} / \mathrm{min}$ under nitrogen. Buoyancy corrections were made by recording baselines with empty crucibles. X-ray fluorescence analyses were carried out in Shimadzu EDX-720 equipment.

\section{$2.2-\underline{N_{2}}$ powders}

The $\mathrm{N}_{2}$ samples were calcined at $900^{\circ} \mathrm{C} / 4 \mathrm{~h}$ and $1200^{\circ} \mathrm{C} / 24 \mathrm{~h}$, with $10^{\circ} \mathrm{C} / \mathrm{min}$ heating and cooling rates.

The thermal profile of the precursor powder was monitored by thermogravimetric analysis in a Netzsch STA 449 analyzer with $\sim 20 \mathrm{mg}$ of sample, heating under argon from 25 to $1200{ }^{\circ} \mathrm{C}$ with $10{ }^{\circ} \mathrm{C} / \mathrm{min}$ heating rate. Buoyancy corrections were made by recording baselines with empty crucibles. The chemical composition was evaluated by quantitative chemical analysis in a WDS Cameca SX-100 electron microprobe, with 15 kV accelerating voltage, probe current $20 \mathrm{nA}$ and beam size $1 \mu \mathrm{m}$. For the analysis, the calcined powders were pressed into $5 \mathrm{~mm}$ diameter pellets and sintered at $1200{ }^{\circ} \mathrm{C}$ for $24 \mathrm{~h}$; the surface was polished and carbon-coated. The composition of the sample was determined using an average of 6-10 points. Both powder samples synthesized in air or under $\mathrm{N}_{2}$ were subjected to powder X-ray diffraction in a

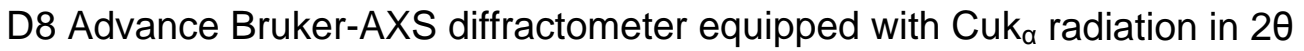
range from 20 to $80^{\circ}$ with a step size $0.02 \%$ s. Jade 6.1 software (Materials Data Inc.) was employed for phase identification of the X-ray data. The lattice parameters were evaluated with the Unit Cell software. 


\subsection{BZY10 compacts}

The calcined BZY10 powders were uniaxially cold pressed at $18 \mathrm{MPa}$ to cylindrical pellets with $5 \mathrm{~mm}$ diameter and $2 \mathrm{~mm}$ thickness. The pellets were embedded in 10 mol\% Ba-excess BZY10 powder, to avoid barium volatilization, inside zirconia crucibles with lids, and sintered in air in a Zircar Hot Spot 110 Furnace at $1600{ }^{\circ} \mathrm{C} / 4 \mathrm{~h}$ with $3^{\circ} \mathrm{C} / \mathrm{min}$ heating and cooling rates.

The investigation of the morphology of calcined powders and their fracture surfaces was carried out in a FEI Inspect F50 scanning electron microscope. The complementary morphological characterization of all calcined samples, produced either in laboratory air or under nitrogen atmosphere, was performed in a FEI Tecnai TF20 field emission gun high-resolution transmission electron microscope.

The electrical conductivity of the sintered pellets was evaluated by impedance spectroscopy with a Hewlett Packard 4192A analyzer connected to a Hewlett Packard series 360 Controller. Silver electrodes were applied onto the parallel sample surfaces. The measurements were performed in laboratory air (65\% R.H.) from 200 to $600{ }^{\circ} \mathrm{C}$ in the $5 \mathrm{~Hz}$ to $1.3 \times 10^{7} \mathrm{~Hz}$ frequency range under $200 \mathrm{mV}$ voltage. Special software was used to collect the [-Z"(f) x Z'(f)] impedance spectroscopy data and also for deconvolution of the impedance diagrams [40] for the evaluation of bulk and grain boundary electrical resistance. The impedance spectroscopy diagrams were normalized by the geometrical factor of the pellets (S/L, $S=$ electrode area, $L=$ pellet thickness).

\section{Results and Discussion}


Figure 1 shows the thermal behavior of both BZY10 samples produced by the OPM under laboratory air (AIR) and under controlled nitrogen atmosphere $\left(\mathrm{N}_{2}\right)$. The mass loss of the AIR sample reached $27.5 \%$, which is $5.5 \%$ higher than the value found for the $\mathrm{N}_{2}$ sample. The thermal event related with the water loss that takes place up to $250{ }^{\circ} \mathrm{C}$ is similar in both samples. The mass loss corresponding to the complete degas/bulk dehydration, which is known to occur between 600 and $700{ }^{\circ} \mathrm{C}$ in protonic conductors, starts at a temperature at least $40{ }^{\circ} \mathrm{C}$ lower in the $\mathrm{N}_{2}$ sample than the AIR sample. Another important observation is the decarbonation events that usually start at approximately $800^{\circ} \mathrm{C}$. A possible carbonate phase in the AIR sample continues to decompose up to $1200{ }^{\circ} \mathrm{C}$ and the heat treatment was not sufficient to complete the decarbonation event as it does not reach constant mass at the end of the measurement. The $\mathrm{N}_{2}$ sample shows a minor mass loss from $800{ }^{\circ} \mathrm{C}$ to $900{ }^{\circ} \mathrm{C}$, and for higher temperatures the sample mass remains approximately constant.

\section{Figure 1}

The thermal behavior indicates that producing BZY10 powders under $\mathrm{N}_{2}$ prevents large contamination with $\mathrm{CO}_{2}$ from the ambient, leading to cleaner particle surfaces than for samples prepared in air.

The chemical and the EDX analyses show that both BZY10 samples obtained by the two different experimental approaches are stoichiometric with formula corresponding to $\mathrm{Ba}_{0.99} \mathrm{Zr}_{0.91} \mathrm{Y}_{0.09} \mathrm{O}_{3-\delta}$.

Figures $2 \mathrm{a}$ and $2 \mathrm{~b}$ illustrate the $\mathrm{X}$-ray diffraction patterns of BZY10 powders synthesized in air and under $\mathrm{N}_{2}$. The cubic perovskite phase was 
indexed (PDF \#06-0399) for all samples. The BZY10 - $\mathrm{N}_{2}$ sample heat treated at $1200{ }^{\circ} \mathrm{C} / 24 \mathrm{~h}$ is single phase while an additional $\mathrm{BaCO}_{3}$ phase (PDF \#5-378) is still present in case of air synthesized samples. The presence of $\mathrm{BaCO}_{3}$ second phase in XRD pattern even after heating to $1200{ }^{\circ} \mathrm{C} / 24 \mathrm{~h}$ is corroborating well with the TGA results for the air synthesized sample. From both TGA and XRD results, it is evident that removing/decomposing $\mathrm{BaCO}_{3}$ secondary phase from the sample synthesized in air is difficult even after heating to $1200{ }^{\circ} \mathrm{C} / 24 \mathrm{~h}$, which is not the case in samples synthesized under controlled atmosphere. The calculated lattice parameters for both air and $\mathrm{N}_{2}$ prepared samples are $4.193 \pm 0.001 \AA$, which is very close to the reported values $[41,42]$.

\section{Figure 2}

Figure 3 shows the scanning electron microscopy images of calcined BZY10 powders. The powders consist of agglomerated nanosized particles, the size and agglomeration increases with increasing calcination temperature, as expected.

\section{Figure 3}

Figure 4 shows the TEM images of BZY10 samples synthesized in air or under $\mathrm{N}_{2}$ after calcination at 900 and $1200{ }^{\circ} \mathrm{C}$. The particles of both samples are more or less agglomerated depending on the experimental condition such as temperature of heat treatment and synthesis approach. Very dense agglomerates constitute the sample produced under laboratory air after calcination at $900{ }^{\circ} \mathrm{C}$. The increase of the heat treatment temperature to 1200 ${ }^{\circ} \mathrm{C}$ promotes particle sintering (neck formation) and a cubic shape can be 
identified with a broad distribution of sizes in which edge lengths were estimated between 20 to $150 \mathrm{~nm}$. The samples produced under nitrogen are less agglomerated after heat treatment at $900{ }^{\circ} \mathrm{C}$, compared to the samples produced in laboratory air. Single cubic particles are still maintained and present a sharper distribution of edge lengths varying between 10 and $20 \mathrm{~nm}$. The heat treatment at $1200{ }^{\circ} \mathrm{C}$ for $24 \mathrm{~h}$ promotes the formation of relatively small agglomerates of sintered nanometric particles.

\section{Figure 4}

This behavior indicates that the particles produced under $\mathrm{N}_{2}$ have cleaner surfaces, are less agglomerated, have better growth control, compared to the samples produced in air.

The powders were uniaxially cold pressed to pellets and sintered in air at $1600{ }^{\circ} \mathrm{C} / 4 \mathrm{~h}$. The samples synthesized under $\mathrm{N}_{2}$ inside a glove box and dried under vacuum at room temperature achieved higher density than the samples synthesized in laboratory air and dried at $80{ }^{\circ} \mathrm{C}$. This behavior suggests that controlling the drying procedure is important for obtaining high quality powder particles, also cleaning the precursor surface by removing water and other contaminant species, avoids particle agglomeration. In addition, the increase of the calcination temperature from 900 to $1200{ }^{\circ} \mathrm{C}$ leads to a decrease in the relative density, which is probably related to particle agglomeration at higher temperatures, inhibiting mass transport during sintering.

Images of the surfaces of the sintered BZY pellets are shown in Figures 5 a-f. The surfaces of sintered pellets using powders synthesized in air 
(Figures $5 \mathrm{a}$ and $5 \mathrm{~b}$ ) show grains of irregular shapes with average sizes increasing with increasing calcination temperature of the powders. On the other hand, sintered pellets from powders synthesized under $\mathrm{N}_{2}$ (Figures $5 \mathrm{c}-5 \mathrm{f}$ ), show submicron grains well attached to each other. Ladder-type larger grains with average size of $500 \mathrm{~nm}$ are observed in pellets sintered from powders calcined at higher temperature $\left(1200^{\circ} \mathrm{C}\right)$. The denser structures of pellets prepared from powders synthesized under nitrogen inside a glove box are responsible for their improved electrical conductivity. The calcination of the powders at $1200{ }^{\circ} \mathrm{C}$ promotes grain growth with consequent enhancement of the electrical conductivity due to the decrease in the grain boundaries density, which promotes the better transfer of charge carriers.

\section{Figure 5}

The impedance plots measured at $530{ }^{\circ} \mathrm{C}$ of the BZY10 sintered samples are shown in Figure 6. For the samples synthesized in air, only one semicircle is resolved. The semicircles start from the origin indicating that the bulk resistance is much smaller than the grain boundary resistance $[14,43,44]$. The analysis of the impedance plots allows the evaluation of the capacitances (Table 1), which could be associated with the major contribution of the grain boundaries $\left(10^{-11} \mathrm{~F} / \mathrm{cm}\right)$. The high grain boundary resistance might be due to a space charge layer, which inhibits the charge carrier transfer at these interfaces.

\section{Figure 6}

Three semicircles are apparent in the impedance diagram of the $\mathrm{N}_{2}$ samples, at high frequencies (HF), medium frequencies (MF) and low 
frequencies (LF). The capacitance values associated to the HF semicircle $\left(10^{-10}\right.$ $\mathrm{F} / \mathrm{cm}-10^{-11} \mathrm{~F} / \mathrm{cm}$ ) indicate the contribution of the grains to the total resistivity, the values corresponding to the MF semicircle $\left(10^{-8} \mathrm{~F} / \mathrm{cm}-10^{-9} \mathrm{~F} / \mathrm{cm}\right)$ are related to grain boundaries [45]; the LF semicircle is due to electrode polarization. The total resistivity (grains and grain boundaries) increases in the following order: (OPM $\left.1200{ }^{\circ} \mathrm{C}-\mathrm{N}_{2}\right)<\left(\right.$ OPM $\left.900{ }^{\circ} \mathrm{C}-\mathrm{N}_{2}\right)<\left(\right.$ OPM $900{ }^{\circ} \mathrm{C}$-AIR $)<$ (OPM $1200{ }^{\circ} \mathrm{C}$-AIR). This behavior is illustrated in the Arrhenius plots of the total conductivity shown in Figure 7. The samples synthesized under nitrogen achieve the higher total conductivities.

\section{Figure 7}

The sample BZY10- $\mathrm{N}_{2}$ heat treated at $1200{ }^{\circ} \mathrm{C} / 24 \mathrm{~h}$ achieved the highest total conductivity, suggesting it is composed of larger grains and/or cleaner intergranular regions. The activation energy was evaluated from the slope of the straight lines in Figure 7 and the values are shown in Table 1, together with the capacitance values. The total conductivity of sintered pellets prepared with powders synthesized under $\mathrm{N}_{2}$ and calcined at $1200{ }^{\circ} \mathrm{C}$ is 120 times higher than the total conductivity of pellets prepared with powders synthesized in laboratory air.

\section{Table 1}

The values of the activation energy $(0.38-0.39 \mathrm{eV})$ agree with reported values $[46,47]$.

\subsection{Comparison with other methods of synthesis}


The main challenges encountered to the use of yttrium-doped barium zirconate solid electrolytes in solid oxide fuel cells are the synthesis of sinteractive powders (not requiring high sintering temperature) and the blocking of protons at the interfaces (that promotes large grain boundary resistivity). Solgel, polyacrilamide, combustion, coprecipitation are synthesis methods used to produce BZY powders with high sinterability to obtain dense compacts after sintering $[16,18,20-23]$. The main advantage of the OPM over other methods is that it leaves no residues $[33,34]$, which could otherwise promote deleterious effects on the proton conductivity. Moreover, stoichiometry is preserved and the primary particles are in the nanosize range with consequent high sinterability of the compacts [35-37]. Therefore, the OPM is a suitable alternative to synthesize high quality SOFC electrolytes. Even though most of those methods produced sinteractive ceramic powders, solving the first challenge, comparison of the electrical performance of consolidated powders using those powders is difficult due to different experimental conditions (steam concentration, water adsorption [43]) for evaluation of the electrical conductivity.

\section{Conclusions}

Yttrium-doped barium zirconate ceramic solid electrolytes were synthesized by the oxidant peroxide method under different ambient conditions, namely, laboratory air and controlled nitrogen atmosphere inside a glove box. The samples made in different synthesis atmosphere, show different electrical behavior. It was found that surface of the powder particles, obtained by limiting water and $\mathrm{CO}_{2}$ content under nitrogen and avoiding prior particle agglomeration 
during the precursor drying procedure, produces denser sintered pellets with improved electrical conductivity (120 times). The emphasis here was to show that powders with particle surfaces nearly free of attached chemical species provide consolidated ceramic pieces with improved electrical properties. Moreover, that procedure may be extended to other chemical methods of synthesis.

\section{Acknowledgements}

We thank FAPESP, Brazil (Procs. 2011/50197-0, 2013/10928-0 and 2013/07296-2) for scholarships to one of the authors (MDG) and financial support, Nick Botto, UCDavis, USA, for the electron microprobe analyses, Prof. E.R. Leite, Federal University of S. Carlos, Brazil, for the TEM analyses. The work at UC Davis received support from the U.S. Department of Energy, Office of Basic Energy Sciences, grant DE-FG02-03ER46053

\section{References}

[1] N.Q. Minh, Ceramic Fuel Cells, J. Am. Ceram. Soc. 76, 3 (1993) 563-588.

[2] S.P.S. Badwal, K. Foger, Solid oxide electrolyte fuel cell review, Ceram. Int. 22, 3 (1996) 257-265.

[3] S.C. Singhal, Advances in solid oxide fuel cell technology, Solid State Ionics 135, 1-4 (2000) 305-313.

[4] H. Yokokawa, N. Sakai, T. Orita, K. Yamaji, Recent developments in solid oxide fuel cell materials, Fuel Cells 1, 2 (2001) 117-131. 
[5] S.C. Singhal, Solid oxide fuel cells for power generation, Wiley Interdisciplinary Reviews - Energy and Environment 3, 2 (2014) 179-194.

[6] S.M. Haile, Fuel cell materials and components, Acta Mater. 51 (2003) 59816000.

[7] A. Orera, P.R. Slater, New Chemical Systems for Solid Oxide Fuel Cells, Chem. Mater. 22 (2010) 675-690.

[8] H. Ding, J. Ge, X. Xue, A ceramic-anode supported low temperature solid oxide fuel cell, Electrochem. Solid-State Lett. 15 (2012) B86.

[9] G.Y. Xie, C. Kim, X.L. Qian, Y.Q. Sun, Review of recent progress in materials for intermediate temperature solid oxide fuel cells, Rare Earth Metal Mater. Eng. 30 (2001) 531-537.

[10] B.C.H. Steele, A. Heinzel, Materials for fuel-cell technologies, Nature 414 (2001) 345-352.

[11] Z. Ghao, L.V. Mogni, E.C. Miller, J.G. Railsback, S.A. Barnett, A perspective on low-temperature solid oxide fuel cells, Energy Environ. Sci. 9 (2016) 1602-1644.

[12] K.D. Kreuer, Proton-Conducting oxides, Annu. Rev. Mater. Res. 33 (2003) 333-359.

[13] S.M. Haile, P.N. Pintauro, Proton transport for fuel cells, J. Mater. Chem. 20 (2010) 6211.

[14] H.G. Bohn, T. Schober, Electrical conductivity of the high-temperature proton conductor $\mathrm{BaZr}_{0.9} \mathrm{Y}_{0.1} \mathrm{O}_{2.95}$, J. Am. Ceram. Soc. 83 (2000) 768-772. [15] E.C.C. De Souza, R. Muccillo, Properties and applications of perovskite proton conductors, Mater. Res. 13 (2010) 385-394. 
[16] P. Babilo, S.M. Haile, Enhanced sintering of yttrium-doped barium zirconate by addition of ZnO, J. Am. Ceram. Soc. 88 (2005) 2362-2368.

[17] K.D. Kreuer, S. Adams, W. Münch, A. Fuchs, U. Klock, J. Maier, Proton conducting alkaline earth zirconates and titanates for high drain electrochemical applications, Solid State Ionics 145 (2001) 295-306.

[18] Y. Yamazaki, R. Hernandez-Sanchez, S.M. Haile, Cation non-stoichiometry in yttrium-doped barium zirconate: phase behavior, microstructure, and proton conductivity, J. Mater. Chem. 20 (2010) 8158.

[19] C. Duan, J. Tong, M. Shang, S. Nikodemski, M. Sanders, S. Ricote, A. Almansoori, R. O'Hayre, Readily processed protonic ceramic fuel cells with high performance at low temperatures, Science 349, 6254 (2015) 1321-1326. [20] A. Magrez, Preparation, sintering, and water incorporation of proton conducting $\mathrm{Ba}_{0.99} \mathrm{Zr}_{0.8} \mathrm{Y}_{0.2} \mathrm{O}_{3-\delta}$ : comparison between three different synthesis techniques, Solid State Ionics 175 (2004) 585-588.

[21] Y. Yamazaki, P. Babilo, S.M. Haile, Defect chemistry of yttrium-doped barium zirconate: A thermodynamic analysis of water uptake, Chem. Mater. 20 (2008) 6352-6357.

[22] B. Bendjeriou-Sedjerari, J. Loricourt, D. Goeuriot, P. Goeuriot, Sintering of $\mathrm{BaZrO}_{3}$ and $\mathrm{SrZrO}_{3}$ perovskites: Role of substitutions by yttrium or ytterbium, J. Alloys Compd. 509 (2011) 6175-6183.

[23] P.I. Dahl, H.L. Lein, Y. Yu, J. Tolchard, T. Grande, M.-A. Einarsrud, C. Kjølseth, T. Norby, R. Haugsrud, Microstructural characterization and electrical properties of spray pyrolyzed conventionally sintered or hot-pressed BaZrO3 and $\mathrm{BaZr}_{0.9} \mathrm{Y}_{0.1} \mathrm{O}_{3-\delta}$, Solid State Ionics 182 (2011) 32-40. 
[24] F. Bozza, Y. Arroyo, T. Graule, Flame spray synthesis of $\mathrm{BaZr}_{0.8} \mathrm{Y}_{0.2} \mathrm{O}_{3-\delta}$ electrolyte nanopowders for intermediate temperature proton conducting fuel cells, Fuel Cells 15 (2015) 588-594.

[25] Y. Yamazaki, R. Hernandez-Sanchez, S.M. Haile, High total proton conductivity in large-grained yttrium-doped barium zirconate, Chem. Mater. 21 (2009) 2755-2762.

[26] Y. Yamazaki, F. Blanc, Y. Okuyama, L. Buannic, J.C. Lucio-Vega, C.P. Grey, S.M. Haile, Proton trapping in yttrium-doped barium zirconate, Nature Mater. 12 (2013) 647-651.

[27] K.D. Kreuer, Aspects of the formation and mobility of protonic charge carriers and the stability of perovskite-type oxides, Solid State Ionics 125 (1999) 285-302.

[28] M.S. Islam, R.A. Davies, J.D. Gale, Proton migration and defect interactions in the $\mathrm{CaZrO}_{3}$ orthorhombic perovskite: A quantum mechanical study, Chem. Mater. 13 (2001) 2049-2055.

[29] R. Hempelmann, C. Karmonik, T. Matzke, M. Cappadonia, U. Stimming, T. Springer, M.A. Adams, Quasielastic neutron scattering study of proton diffusion in $\mathrm{SrCe}_{0.95} \mathrm{Yb}_{0.05} \mathrm{H}_{0.02} \mathrm{O}_{2.985}$, Solid State Ionics 77 (1995) 152-156.

[30] K.D. Kreuer, On the development of proton conducting materials for technological applications, Solid State Ionics 97 (1997) 1-15.

[31] R.A. Davies, M.S. Islam, J.D. Gale, Dopant and proton incorporation in perovskite-type zirconates, Solid State Ionics 126 (1999) 323-335. 
[32] M.D. Gonçalves, P.S. Maram, R. Muccillo, A. Navrotsky, Enthalpy of formation and thermodynamic insights into yttrium doped $\mathrm{BaZrO}_{3}$, J. Mater. Chem. A 2 (2014) 17840-17847.

[33] E.R. Camargo, J. Frantti, M. Kakihana, Low-temperature chemical synthesis of lead zirconate titanate (PZT) powders free from halides and organics, J. Mater. Chem. 11 (2001) 1875-1879.

[34] E.R. Camargo, M. Popa, J. Frantti, M. Kakihana, Peroxide-based route free from halides for the synthesis of lead titanate powder, Chem. Mater. 13 (2001) 3943-3948.

[35] E.R. Camargo, F.L. Souza, E.R. Leite, M. Kakihana, Structural and electrical characterization of dense lead zirconate titanate ceramics synthesized by the oxidant-peroxo wet-chemical route, J. Appl. Phys. 96 (2004) 2169. [36] A.H. Pinto, F.L. Souza, A.J. Chiquito, E. Longo, E.R. Leite, E.R. Camargo, Characterization of dense lead lanthanum titanate ceramics prepared from powders synthesized by the oxidant peroxo method, Mater. Chem. Phys. 124 (2010) 1051-1056.

[37] A.H. Pinto, F.L. Souza, E. Longo, E.R. Leite, E.R. Camargo, Structural and dielectric characterization of praseodymium-modified lead titanate ceramics synthesized by the OPM route, Mater. Chem. Phys. 130 (2011) 259-263.

[38] M.D. Gonçalves, R. Muccillo, Properties of yttrium-doped barium zirconate ceramics synthesized by the oxidant-peroxo method, Ceram. Int. 40 (2014) 911917.

[39] M.S. Kaliszewski e A.H. Heuer, Alcohol Interaction with Zirconia Powders, J. Am. Ceram. Soc. 73 (1990) 1504-1509. 
[40] M. Kleitz, J.H. Kennedy, in: P. Vashishta, J.N. Mundy, G.K. Shenoy, (Eds.), Fast Ion Transport in Solids, Elsevier North Holland, The Netherlands, 1979, pp. 185-188.

[41] T. Schober, H.G. Bohn, Water vapor solubility and electrochemical characterization of the high temperature proton conductor $\mathrm{BaZr}_{0.9} \mathrm{Y}_{0.1} \mathrm{O}_{2.95}$, Solid State Ionics 127 (2000) 351-360.

[42] Z. Khani, M. Taillades-Jacquin, G. Taillades, M. Marrony, D.J. Jones, J. Rozière, New synthesis of nanopowders of proton conducting materials. A route to densified proton ceramics, J. Solid State Chem. 182 (2009) 790-798. [43] S. Tao, J.T.S. Irvine, Conductivity studies of dense yttrium-doped $\mathrm{BaZrO}_{3}$ sintered at $1325^{\circ} \mathrm{C}, \mathrm{J}$. Solid State Chem. 180 (2007) 3493-3503. [44] P. Babilo, T. Uda, S.M. Haile, Processing of yttrium-doped barium zirconate for high proton conductivity, J. Mater. Res. 22 (2007) 1322-1330. [45] J.G. Fletcher, A.R. West, J.T.S. Irvine, The AC impedance response of the physical interface between yttria-stabilized zirconia and $\mathrm{YBa}_{2} \mathrm{Cu}_{3} \mathrm{O}_{7-\mathrm{x}}, \mathrm{J}$.

Electrochem. Soc. 142, 8 (1995) 2650-2654.

[46] S. Imashuku, T. Uda, Y. Nose, Y. Awakura, Effect of isovalent cation substitution on conductivity and microstructure of sintered yttrium-doped barium zirconate, J. Alloys Compd. 490 (2010) 672-676.

[47] S. Ricote, N. Bonanos, A. Manerbino, N.P. Sullivan, W.G. Coors, Effects of the fabrication process on the grain-boundary resistance in $\mathrm{BaZr}_{0.9} \mathrm{Y}_{0.1} \mathrm{O}_{3-\delta}, \mathrm{J}$. Mater. Chem. A 2, 38 (2014) 16107-16115.

[48] S. Wang, Y. Liu, J. He, F. Chen, K.S. Brinkman, Spark-plasma-sintered barium zirconate based proton conductors for solid oxide fuel cell and 
hydrogen separation applications, Int. J. Hydrogen Energy 40 (2015) 57075714. 


\section{Figure Captions}

Fig. 1. Thermogravimetric curves of the yttrium-doped barium zirconate precursor powders synthesized by the oxidant peroxide method in laboratory air and under nitrogen atmosphere.

Fig. 2. X-ray diffraction patterns of calcined BZY10 powders synthesized by the oxidant peroxide method. a: under laboratory air and b: under nitrogen atmosphere.

Fig. 3. Scanning electron microscopy micrographs of BZY10 powders synthesized under laboratory air $(\mathrm{a}, \mathrm{b})$ and under nitrogen atmosphere $(\mathrm{c}, \mathrm{d})$ heat treated at $900{ }^{\circ} \mathrm{C} / 4 \mathrm{~h}(\mathrm{a}, \mathrm{c})$ and $1200^{\circ} \mathrm{C} / 24 \mathrm{~h}(\mathrm{~b}, \mathrm{~d})$.

Fig. 4. High resolution transmission electron microscopy images of BZY10 powders synthesized by the oxidant peroxide method and calcined at $1200^{\circ} \mathrm{C}$. The (a) images show different particles agglomerate at (b) zoom of the delimited regions in (a).

Fig. 5. FEG-SEM micrographs of surfaces of sintered pellets using powders synthesized in air and calcined at $900{ }^{\circ} \mathrm{C} / 4 \mathrm{~h}$ (a) and at $1200{ }^{\circ} \mathrm{C} / 24 \mathrm{~h} \mathrm{(b)}$; under nitrogen and calcined at $900{ }^{\circ} \mathrm{C} / 4 \mathrm{~h}\left(\mathrm{c}\right.$, e) and at $1200^{\circ} \mathrm{C} / 24 \mathrm{~h}(\mathrm{~d}, \mathrm{f})$. 
Fig. 6. Impedance plots of $10 \mathrm{~mol} \%$ yttrium-doped barium zirconate sintered pellets measured at $530{ }^{\circ} \mathrm{C}$. Numbers stand for $\log \mathrm{f}(\mathrm{f}: \mathrm{Hz})$. Sintered pellets using powders synthesized in air and calcined at $900{ }^{\circ} \mathrm{C} / 4 \mathrm{~h}(\mathrm{a})$ and at 1200 ${ }^{\circ} \mathrm{C} / 24 \mathrm{~h}(\mathrm{~b})$; under nitrogen and calcined at $900{ }^{\circ} \mathrm{C} / 4 \mathrm{~h}$ (c) and at $1200{ }^{\circ} \mathrm{C} / 24 \mathrm{~h}$ (d).

Fig. 7. Arrhenius plots of total electrical conductivity of yttrium-doped barium zirconate pellets prepared by the oxidant peroxide method in laboratory air (AIR) and under nitrogen atmosphere $\left(\mathrm{N}_{2}\right)$.

\section{Table Caption}

\section{Table 1}

Total electrical conductivity $\left(\sigma_{\mathrm{T}}\right)$ and activation energy obtained from the Arrhenius plots and capacitance values of the yttrium-doped barium zirconate synthesized by the oxidant peroxide method in laboratory air (AIR) and under nitrogen atmosphere $\left(\mathrm{N}_{2}\right)$. 
Figure(s)

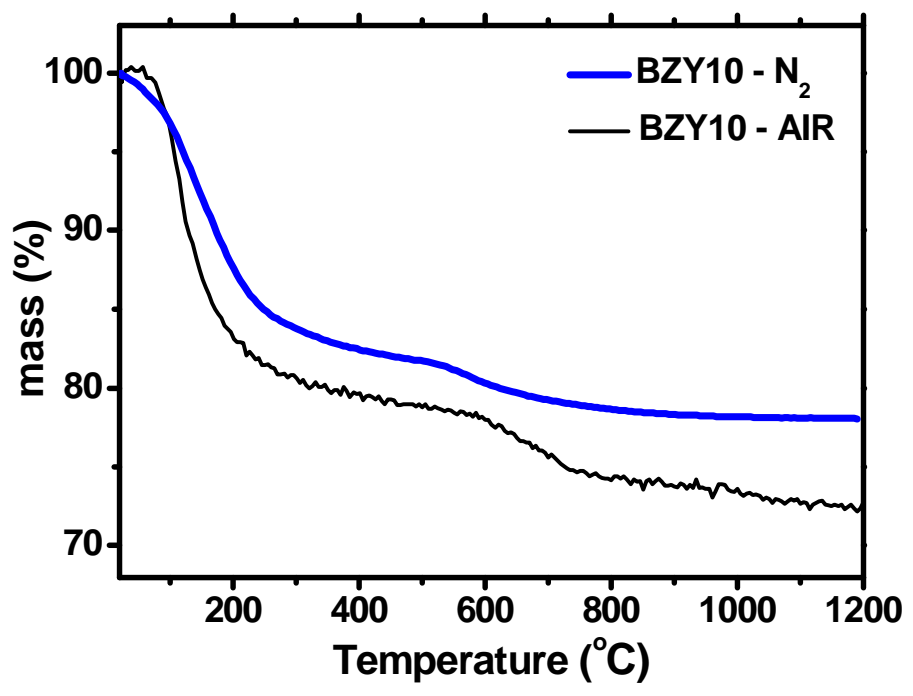

Figure 1 

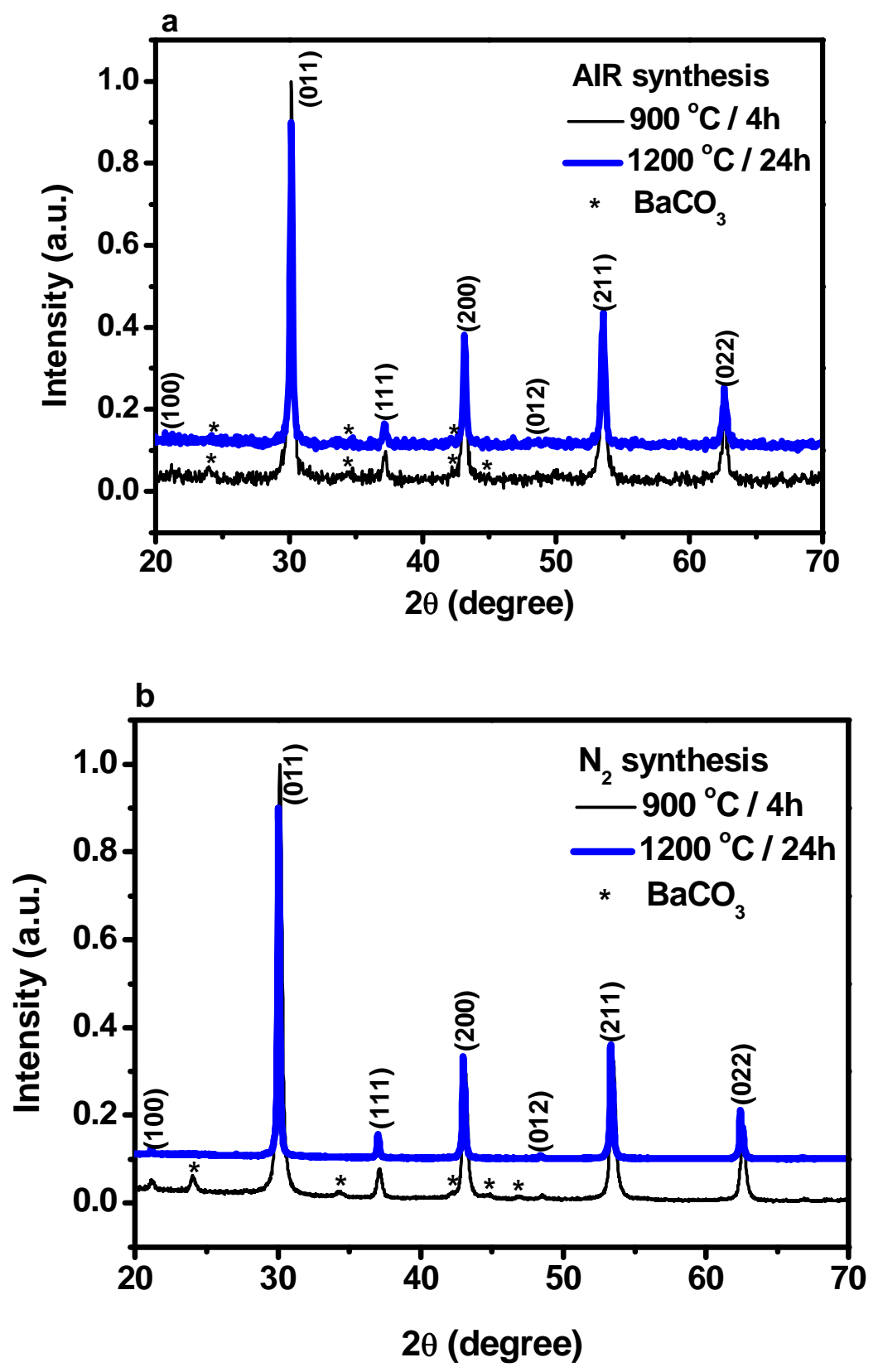

Figure 2 

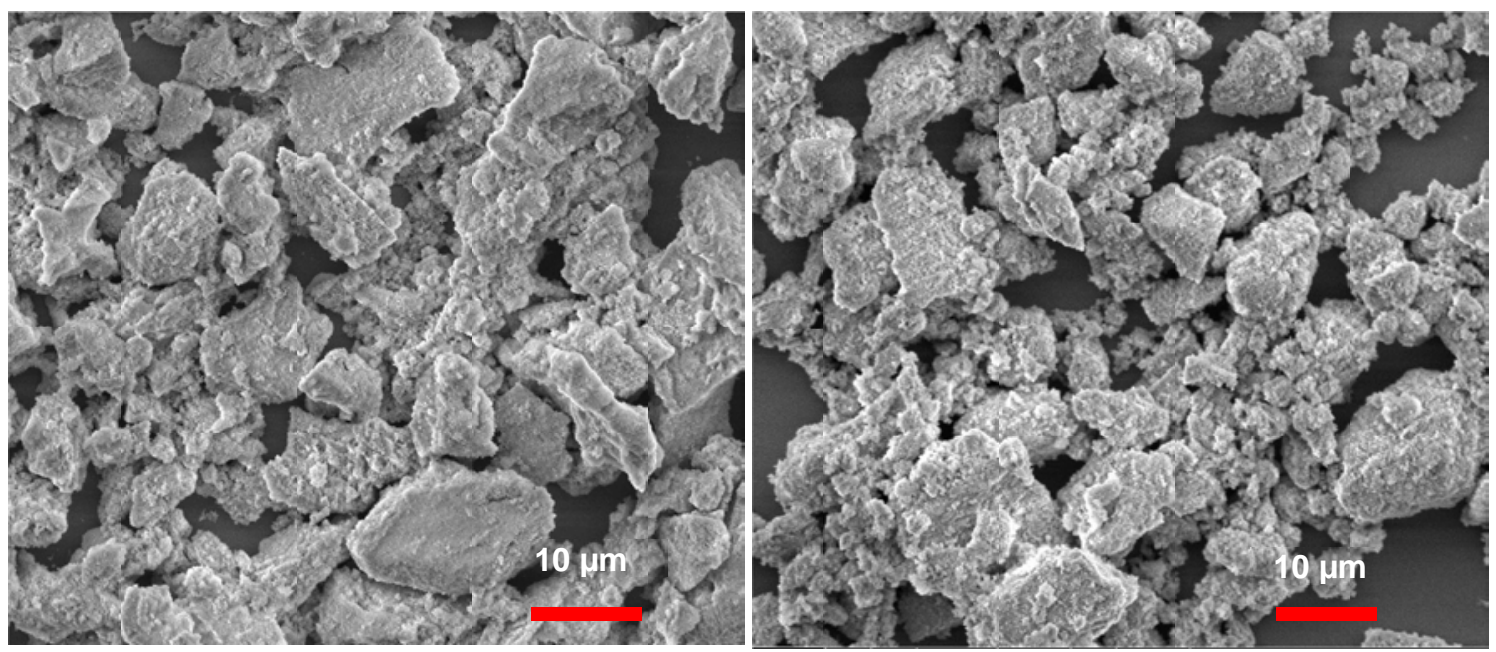

a - 900 AIR

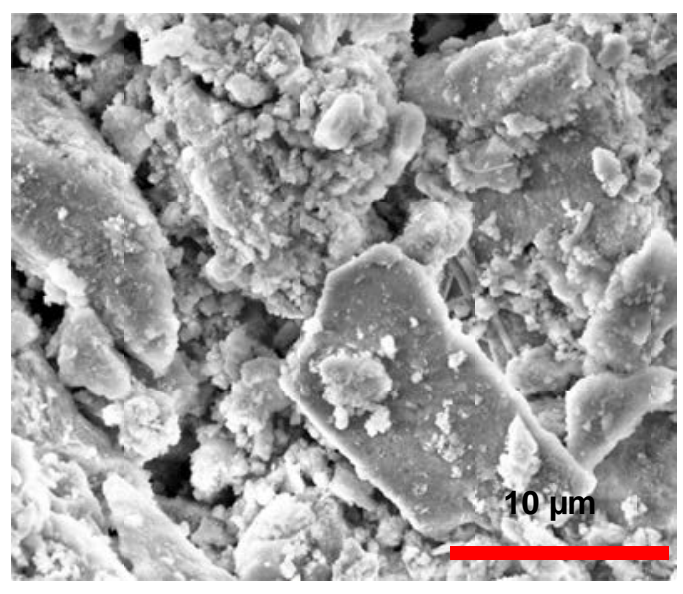

C - $900 \mathrm{~N}_{2}$ b - 1200 AIR

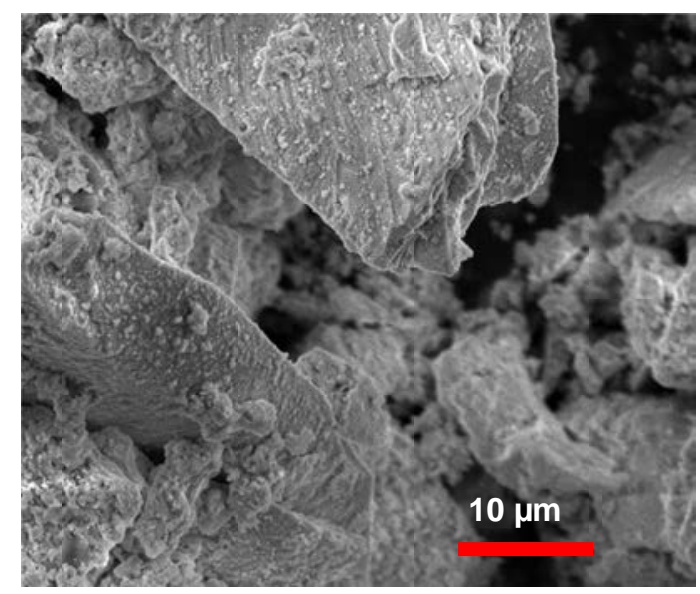

d - $1200 \mathrm{~N}_{2}$

Figure 3 

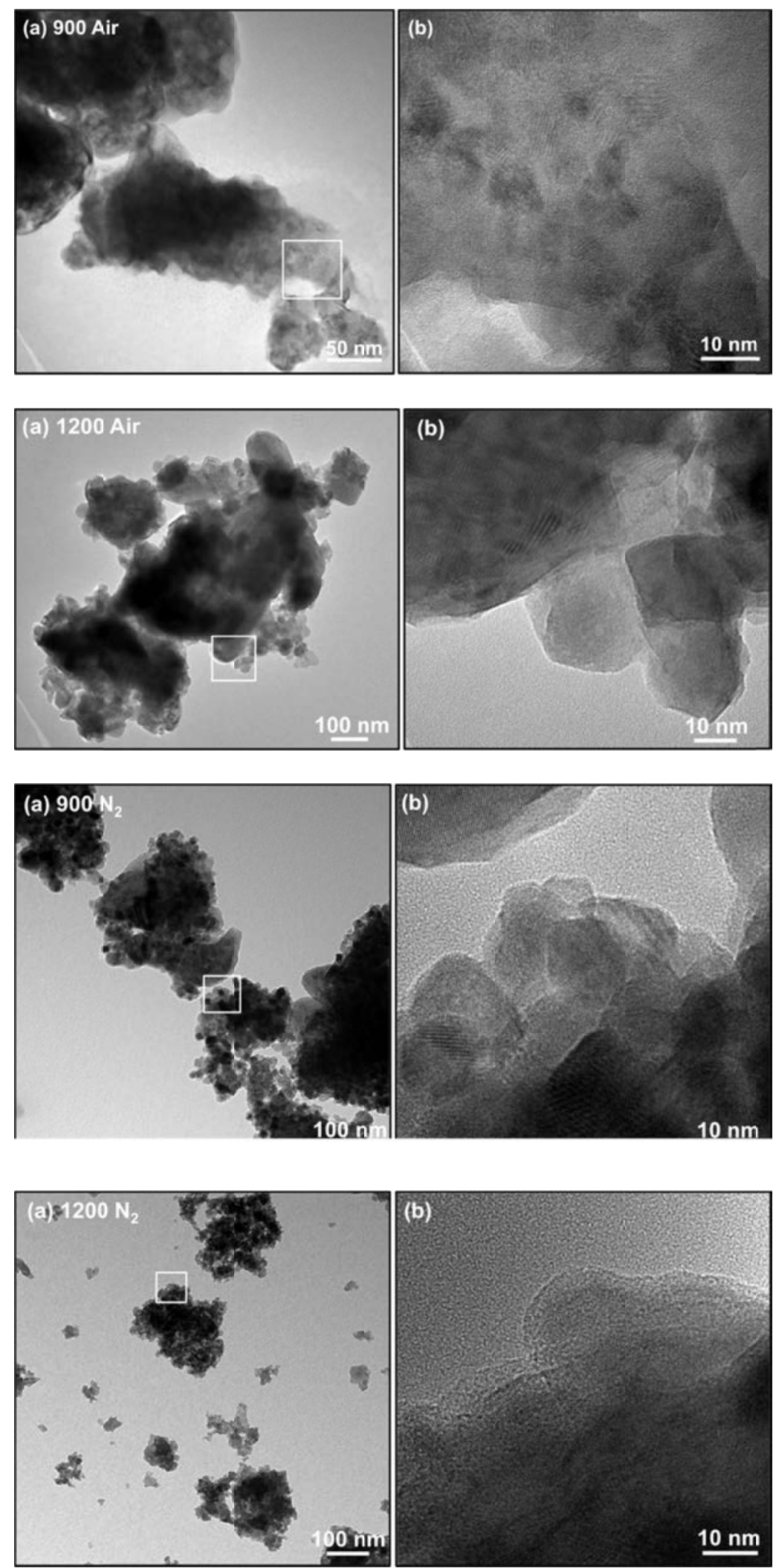

Figure 4 

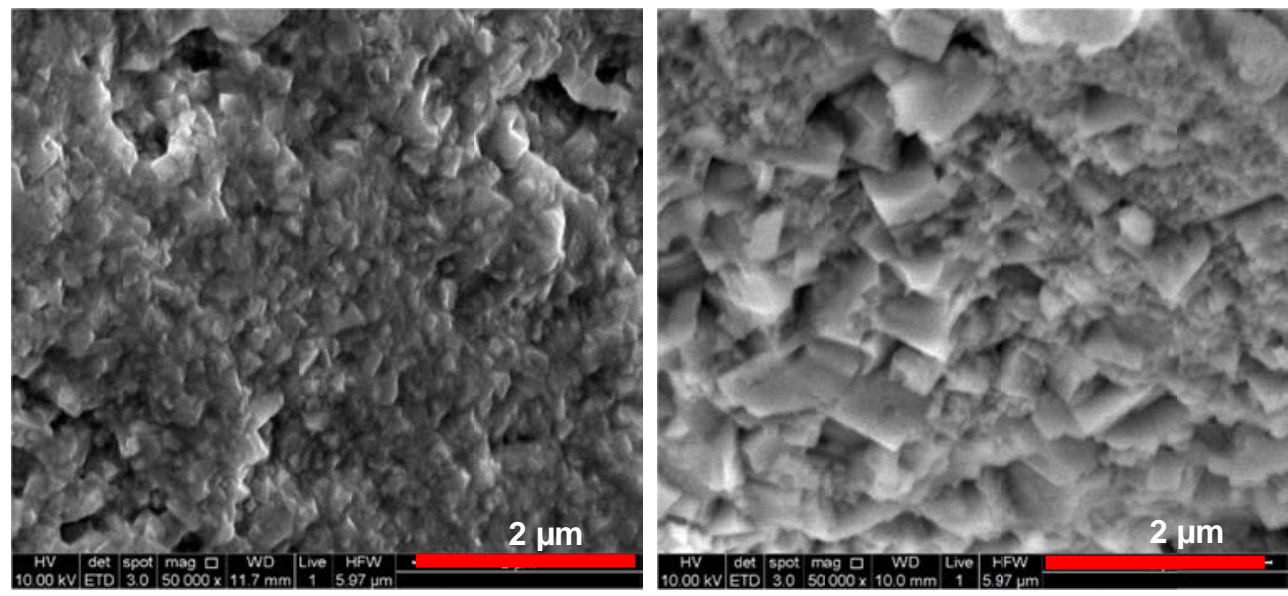

a - 900 AIR

b - 1200 AIR
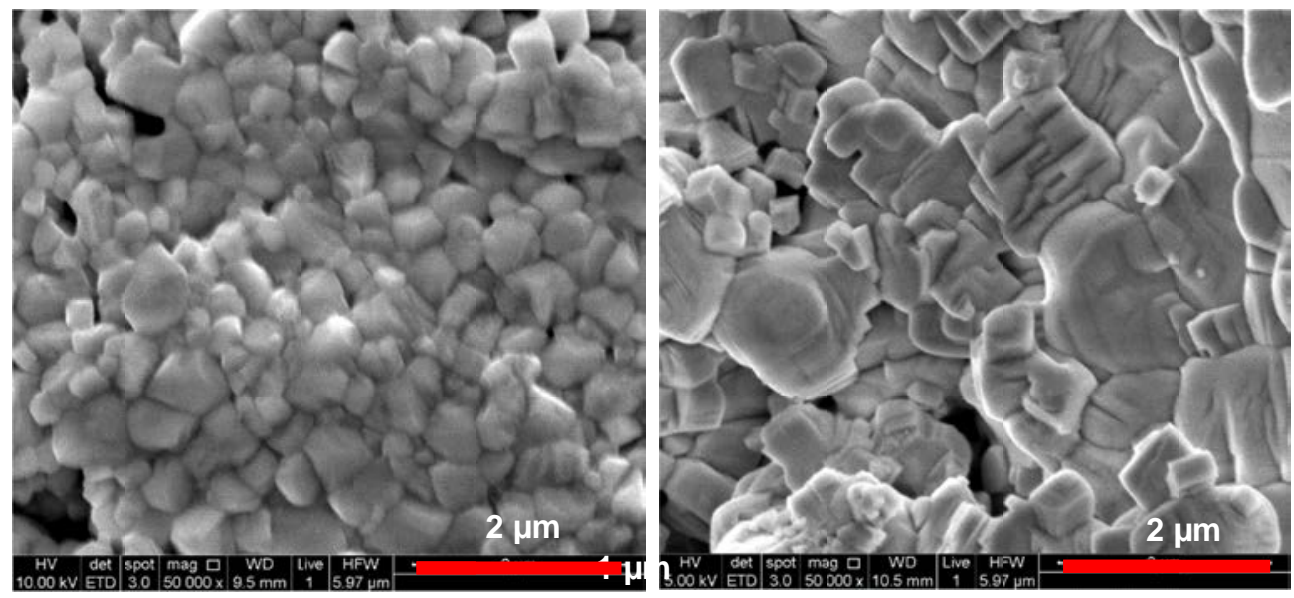

C $-900 \mathrm{~N}_{2}$

d - $1200 \mathrm{~N}_{2}$
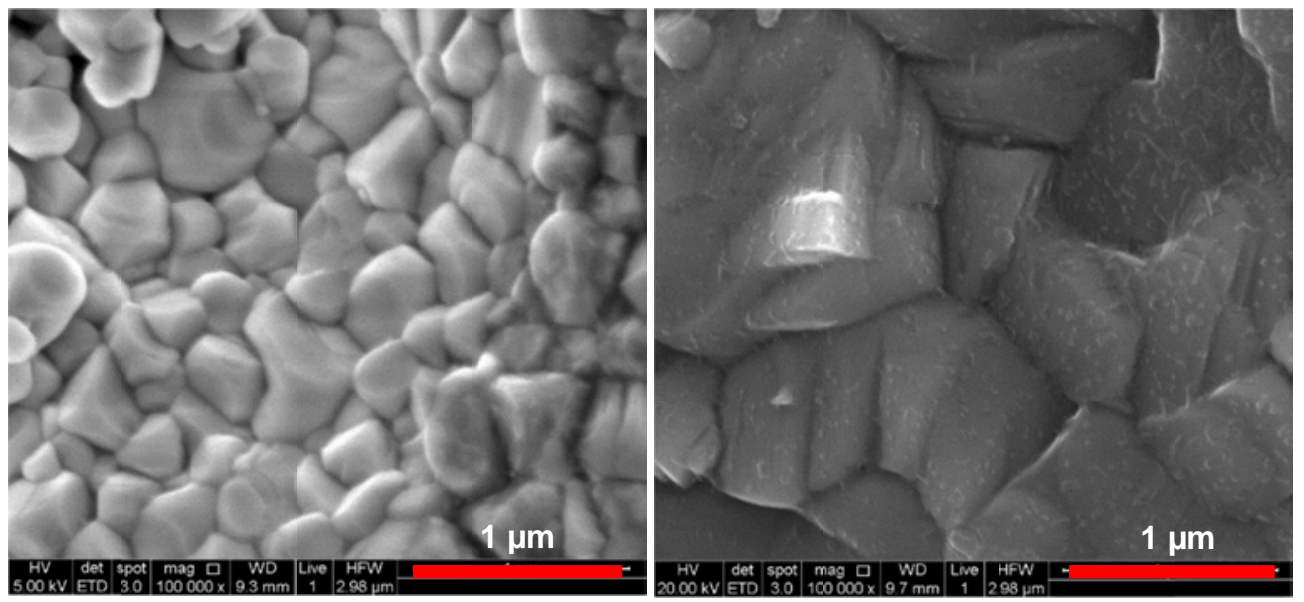

e - $900 \mathrm{~N}_{2}$

f - $1200 \mathrm{~N}_{2}$

Figure 5 

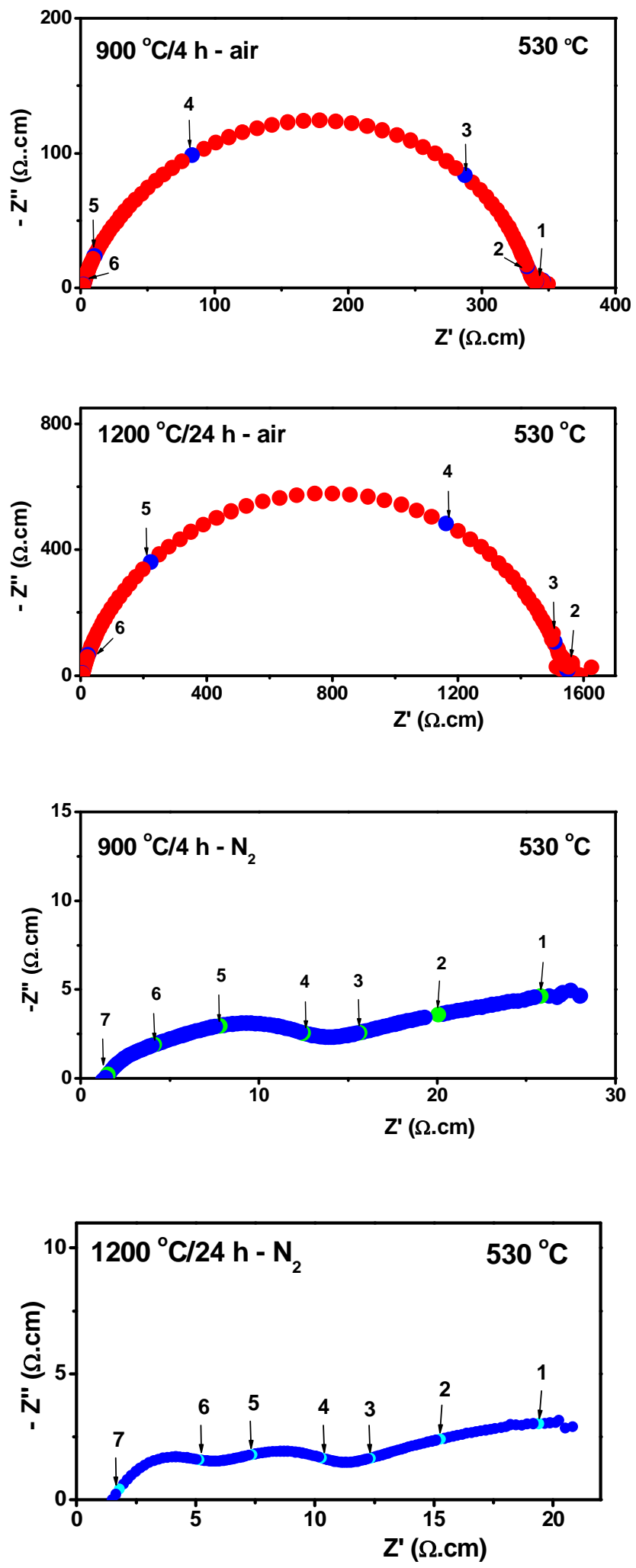

Figure 6 


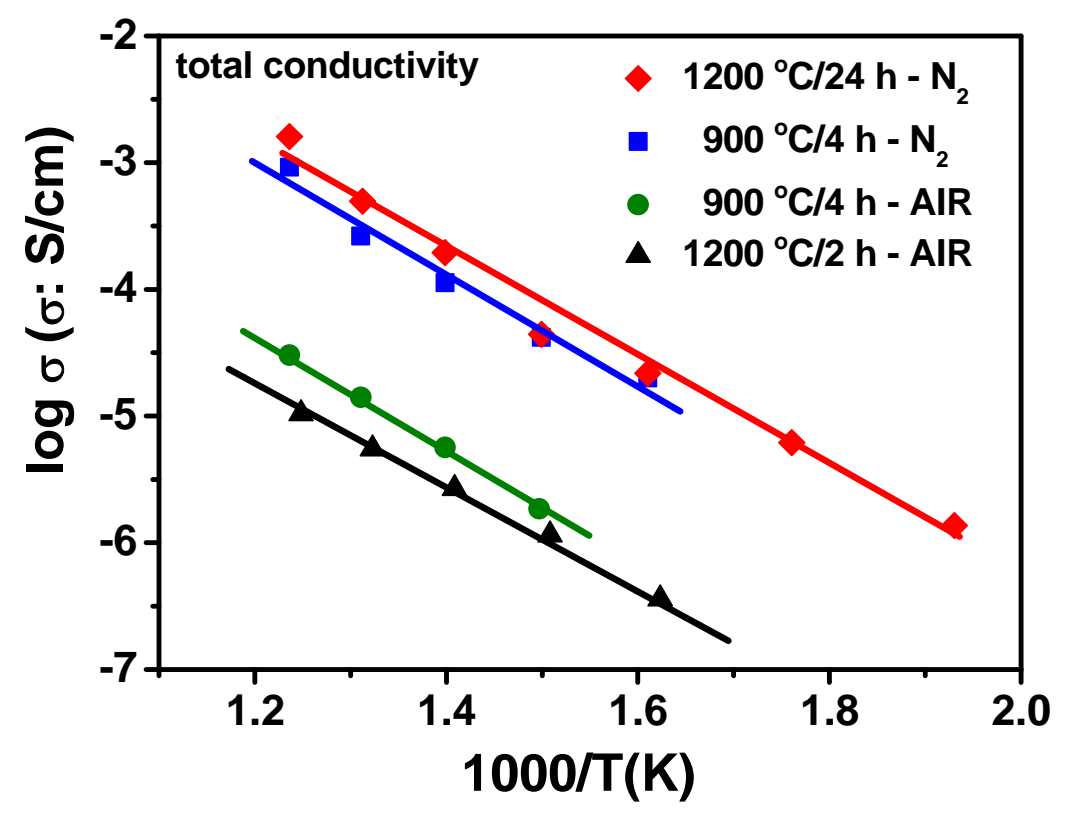

Figure 7 
Table 1

Total electrical conductivity $\left(\sigma_{T}\right)$ and activation energy obtained from the Arrhenius plots and capacitance values of samples synthesized in laboratory air (AIR) and under nitrogen $\left(\mathrm{N}_{2}\right)$.

\begin{tabular}{|c|c|c|c|c|}
\hline \multirow[t]{2}{*}{ Sample } & \multirow{2}{*}{$\begin{array}{c}\sigma_{\mathrm{T}} \text { at } 600{ }^{\circ} \mathrm{C} \\
10^{-5} \mathrm{~S} / \mathrm{cm}\end{array}$} & \multirow{2}{*}{$\begin{array}{l}\mathrm{Ea} \\
\mathrm{eV}\end{array}$} & \multicolumn{2}{|c|}{$\mathrm{F} / \mathrm{cm}$} \\
\hline & & & $\mathrm{HF}\left(10^{-11}\right)$ & LF $\left(10^{-9}\right)$ \\
\hline $900{ }^{\circ} \mathrm{C}-\mathrm{AIR}$ & 4.5 & 0.38 & \multicolumn{2}{|c|}{3.6} \\
\hline $1200^{\circ} \mathrm{C}-\mathrm{AIR}$ & 1.0 & 0.39 & \multicolumn{2}{|c|}{4.5} \\
\hline $900{ }^{\circ} \mathrm{C}-\mathrm{N}_{2}$ & 113 & 0.38 & 13.7 & 4.4 \\
\hline $1200{ }^{\circ} \mathrm{C}-\mathrm{N}_{2}$ & 120 & 0.38 & 5.6 & 11.6 \\
\hline
\end{tabular}

